\title{
USING OF RECYCLED MATERIALS TO PROTECT THE WORKING AND NATURAL ENVIRONMENT BY REDUCING NOISE AND VIBRATION
}

\author{
ŽIARAN Stanislav ${ }^{1}$, ŠOOŠ Lubomír ${ }^{1}$, CHLEBO Ondrej ${ }^{1}$ \\ ${ }^{l}$ Slovak University of Technology in Bratislava, Faculty of Mechanical Engineering, \\ Institute of manufacturing systems, environmental technology and quality management, \\ Nám. slobody 17,812 31 Bratislava, Slovakia, e - mail: stanislav.ziaran@stuba.sk
}

\begin{abstract}
The aim of the article is to define the conditions for the use of recycled resilient materials in the reduction of noise and vibration as an integral part of the mounting and installation of mechanical systems in the work and natural environment. Based on the frequency spectrum, the vibro-isolation efficiency of the vibro-isolators and the viscoelastic materials used is analysed. The solution of this problem is based on the theoretical knowledge and methodology of the transmission of vibration-sound waves. The measurements of the vibration at the sources and along the path of transmission were performed for different recycled materials to compare experimental results with theory.
\end{abstract}

KEYWORDS: machine, structure, recycled material, measurement, FFT analysis, application

\section{$1 \quad$ Introduction}

Mechanical vibration and damping by vibration isolators and/or recycled resilient (viscoelastic) materials constitute the two most widely applicable means for the control of vibration structure-borne sound, particularly in the low and audio frequency range. Vibration isolation in essence involves the use of connection between a source of vibration and an environment to be protected, so that this environment vibrates less than when a rigid connection is used. In some typical situations the source consists of a vibrating mechanical system and the item to be protected is a receiving structure, e.g. the mounting base supported by the mechanical systems, car bodies, nearby surroundings, for instance, other machines, railways and tramways, technological and building structures, human $[9,11,15,18]$. Many salient features of vibration can be analysed in terms of a simple model consisting of a rigid body that is connected to a support via a linear spring and that is constrained to translate in direction of a single axis (e.g. recirculation fan, air-conditioning units, cogeneration units). More complex models are needed to solve the situations where the magnitude of excitation depends on the motions and where an additional spring-mass system is inserted between the mounting base and the protected environment, and/or at comparatively high frequencies where the isolator mass plays a significant role or where the isolated recycled material does not behave as rigid bodies (e.g. vibration isolation of a mounting base, rails). Other complications arise because of non-uniaxial motion causing nonlinearities (e.g. combustion engine [14]). Damping refers to reduce of mechanical energy from given vibration. This reduction may result from transfer of energy to structural components, fluids, or vibration modes that are not important or from conversion of mechanical energy into other forms. Various measures of damping are in use. Most are based on observation of the effects that damping has on the motions of simple systems. Data on the damping inherent in materials cover a wide range, extending from comparatively low damping for high-strength structural materials to very high damping for some viscoelastic materials (typically, plastics or elastomers) with limited strength. Structural components that are 
acceptably strong and that also exhibit relatively high damping may be obtained by combining one high-damping viscoelastic materials with another recycled materials in the form of added layers or in sandwich arrangements. The damping efficiency of the vibration is significantly dependent on the dynamic transfer stiffness of isolators [6, 19].

Vibro-isolation is also used where it is not possible to remove the source of significant dynamic load of the surrounding machines with a possible dynamic influence of newly installed machinery, technological and building structures, railway and tramways. Vibro-isolation reduces any energy transfer of unwanted dynamic loads (vibration, shocks, impacts) from the source to the surrounding machinery and structures (source isolation, protection against vibration emissions) to dynamically protect other machinery, technological and building structures, as well as people from vibration energy received from their surroundings (isolation of the receiver, protection against immissions). In both cases, passive isolators of dynamic load (vibro-isolators) form a system of mass - elastic element (energy absorber), whose dynamic transmission is critically influenced by the properties of the source of dynamic load [8]. In practice, recycled resilient materials based on rubber and textile fibers or a combination of both are often used as an elastic element. The design of a vibration-isolating system requires complete and detailed knowledge of all factors that affect machinery, or technological and building structures and the effective application of vibration-isolation of components, their placement or application in contact areas with buildings [16]. Recycled resilient materials are applied in vibro-isolators in the mounting of machines sensitive to dynamic loads, technological and building structures, rails and railways.

For the required reduction of the dynamic load of machines and structures associated with the design of effective measures, it is generally necessary to perform a detailed technical, functional and spatial analysis of those mechanical systems that generate significant dynamic loads to the environment. It is desirable to perform technical measurements of vibration, shocks and impacts and their transmission to the immediate vicinity, including spectral analysis at the location of the machine or structure and at the location of the propagation energy of vibration, shocks and impacts, for each significant source generating dynamic loads to the environment. The dynamic analysis of these vibration sources also focuses on the assignment of added value (corrections) in the generation of energetically powerful discrete vibration frequencies, highenergy impulse and impact vibration, low-frequency vibration, shocks and impacts.

The structure of materials that significantly absorbs the energy of sound is porous or fibrous. The structural pores of the material are interconnected, which allows sound energy to penetrate into the interior of the material. These materials are used in the form of mats, carpets, coatings, boards, cardboard or various pre-molded elements made of mineral or organic fibers, polyurethane foam, crushed textiles, such as recycled materials manufactured by INTERTECH Plus (CONIRAP), STERED and GETZNER. These materials contain open pores (cavities) with typical dimensions up to $1 \mathrm{~mm}$, which are far smaller than the wavelength of acoustic waves or air cavities between the fibers of the material. The most important physical property of absorbent materials is the resistance that the material exerts on the flowing air stream. The density of the material is also of great importance and it depends on the porosity of the material, i.e. the percentage of the volume of the cavities. In some circumstances, there is also overall elasticity, i.e. the elasticity of the material, including the cavities. What has to be taken into account in the accurate analysis is not only the spatial orientation of the fibers but also obstruction in the passage through cavities. Important parameters of absorbing materials are also complex acoustic impedance and complex sound propagation constant. 


\section{Goals, instrumentation and methodology}

\subsection{Goals of the paper}

The goals of the paper are a) to investigate and analyse the transmission of structure-borne vibro-sound energy flow at a deterministic excitation by the vibration exciter through isolators and recycled resilient material in relation to their surroundings, and to b) experimentally confirm the theory necessary to be implemented in the vibro-isolation elements. The autospectrum of the measured acceleration vibration signals, before and after the vibro-isolating materials, was compared and analysed. The aim of the article is also to define the conditions for using recycled materials in reducing noise and vibration as an integral part of the assembly and installation of mechanical systems at work and in the natural environment.

\subsection{Instrumentation and methodology}

The vibration signal with varying frequency was generated by the inertial vibration exciter TIRAvib TV 51165-IN, and signal generator TEKTRONIX (see Fig. 2-right) and the transmission loss on the components from the recycled resilient materials was performed using the FFT analyser PULSE platform. The measurement system consists of a piezoelectric accelerometer with a frequency range from $1 \mathrm{~Hz}$ to $10 \mathrm{kHz}$, seismic accelerometer for low frequency vibration from $0.1 \mathrm{~Hz}$ to $1.5 \mathrm{kHz}$, and display and memory module. The subject of the research was recycled materials based on rubber and textile fibers (Fig. 1-right). To identify the transmission loss of the recycled resilient material more precisely at low frequencies, the fast Fourier transform (FFT) analysis was carried out. The methodology presented in the article can also be applied to other excitation sources of vibration. The measurement of the investigated objects complied with ISO 5348 guidelines for accelerometers and corresponded with our work practice in previous experiments $[4,20]$. The goal was to ensure that the sensors would correctly reproduce the motion of the analysed components without interfering with the response. Besides the frequency range, it is also very important to select the appropriate type of averaging with respect to signal type, as well and number of averages per unit time, as well as a suitable time interval [10]. Hanning's window with linear averaging and with $66.67 \%$ overlap gives complete uniform weighting, which is useful for analysing generated signal varying from zero to a specified upper limit. The FFT analysis results are presented via square-root of single-side amplitude spectrum.
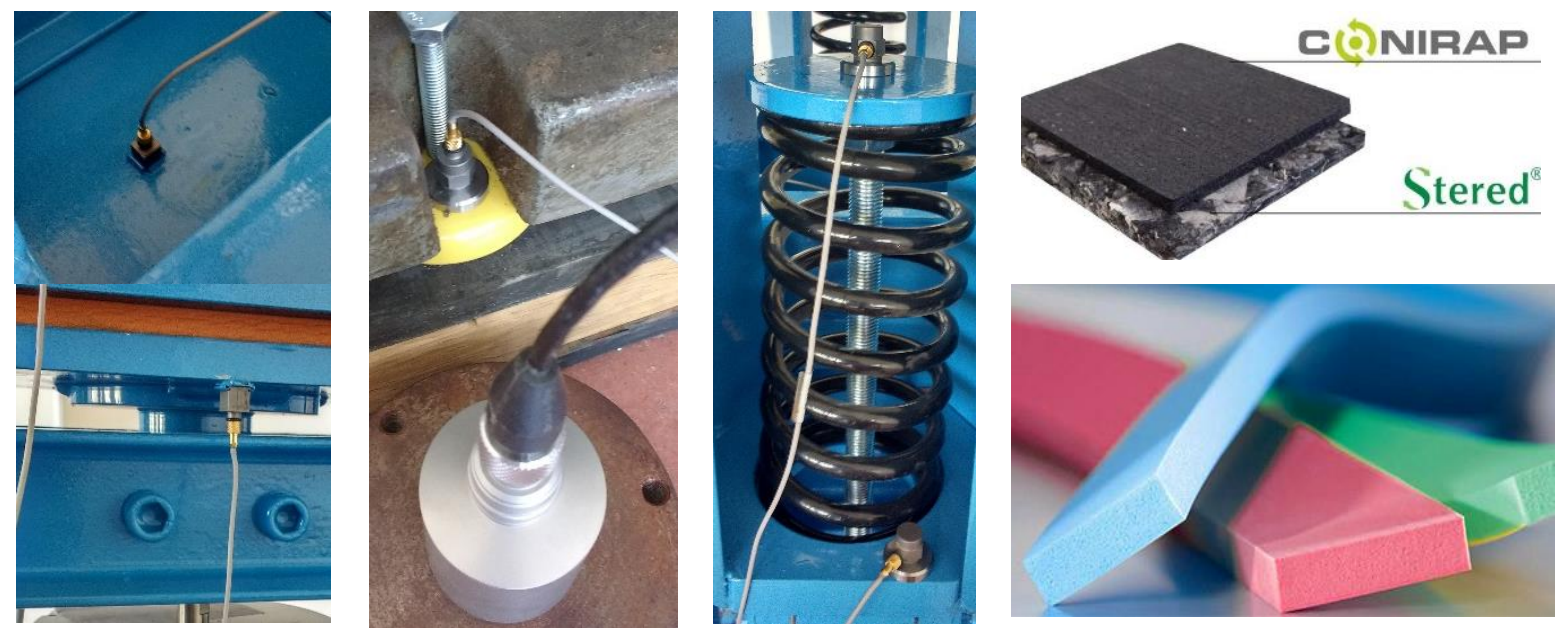

Fig. 1 Vibration acceleration measuring points to determine the transmission attenuation, natural frequencies of the test equipment components and the environment, and test objects

The sensors sensing the changing acceleration of the mechanical vibration were fastened by means of a magnet on an input metal plate representing the source of vibration (exciter) and an 
output metal plate representing the receiving structure of the test device (Fig. 1-left). The goal was to ensure that the sensors would accurately reproduced the motion of the analysed components without interfering with the response. A sample of the test material was placed between the two steel plates to determine its transmission attenuation (Fig. 1-right). The transmission attenuation, calculated from the measured vibration accelerations, was measured at different loads of the test sample. At the same time, the response of vibrations of construction materials in the mounting of the test equipment and the response of the springs of the test equipment itself were measured (Fig. 1-in the center). The aim was to determine the natural frequencies of the natural shapes of buildings and the transmission of excited vibrations by springs, which can affect the transmission attenuation of the tested sample from recycled material.

\section{Theoretical analysis of vibro-isolation and absorption of vibro-sound energy}

\subsection{Transmission loss of the recycled viscoelastic material}

The measurement of transmission loss assumes that the recycled viscoelastic (resilient) material behaves linearly and that it has negligible mass compared to the mass loading. These main conditions are satisfied for the investigated frequency range of vibration. The method enables to determine the impedance of the viscoelastic material when loaded by a mass providing a compressive force equivalent to that found when the recycled viscoelastic material is used usually between the machines as a source of vibration, which is represented by vibration exciter (input) and receiving structure (output). Hence, the system consists of three main blocks, which respectively represent the vibration source, isolator from viscoelastic material and the receiving system respectively (Fig. 2). A fixed contact is assumed at each connection between the vibration source and vibro-isolator and between the vibro-isolator and the receiver. This is done by measuring the transmission function of the mass-loaded material at all the required frequencies [17]. The methodology uses a vibration excitation system, above which the viscoelastic material is placed with the loading mass $m$ (vehicle body, mounting support, building and technological structure, i.e. pipe, as a receiver) on the top of the vibro-isolators.

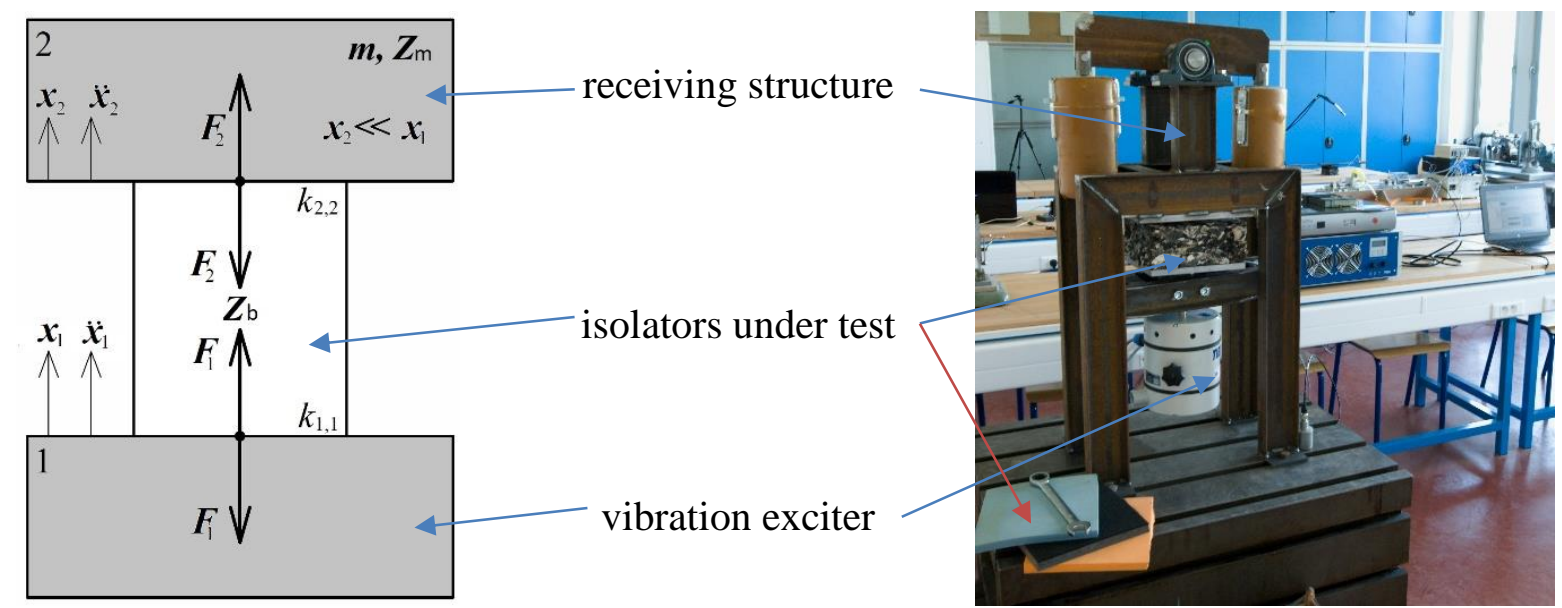

Fig. 2 Schema of the mechanical vibration source - vibro-isolators - receiver structure and the corresponding test equipment

Two sensors measure the acceleration of source vibration on the machine, $\ddot{x}_{1}$, represented by the exciter, and the mechanical vibration acceleration at the receiving structure of mass $m, \ddot{x}_{2}$, (Fig. 2-left).

If the tested recycled resilient element has negligible mass, the equation of motion for the receiving structure, which is considered as a rigid body, becomes 


$$
\bar{n} \bar{y}=7(\bar{x}-\bar{y})
$$

and from this relation the mechanical impedance of the resilient material is

$$
Z_{\mathrm{m}}=\frac{\mathrm{j} \omega m}{\left[\frac{A_{1}}{A_{2}}\right]-1}
$$

and at a single frequency, it follows that

$\frac{A_{1}(\mathrm{j} \omega)}{A_{2}(\mathrm{j} \omega)}=$ magnitude $\times[\cos ($ phase $)+\mathrm{j} \sin ($ phase $)]$

where

$A_{i}(\mathrm{j} \omega) \quad$ is Fourier's transformation of vibration acceleration $\ddot{x}_{i}$;

magnitude - the magnitude of the ratio denoted by $A_{1} / A_{2}$;

phase $\quad$ - the phase difference between $A_{1}$ and $A_{2}$.

If only the receiver structure of mechanical impedance of resilient element $Z_{\mathrm{b}}$ is under consideration, the equation of motion can be expressed as

$$
Z_{\mathrm{b}} \dot{x}_{2}=-Z_{\mathrm{m}}\left(\dot{x}_{2}-\dot{x}_{1}\right)
$$

From Eq. (3) the required vibration transmissibility or transmission function when the viscoelastic material is loaded by the receiving structure (see Fig. 2) can be written as

$$
T=\left|\frac{\dot{x}_{2}}{\dot{x}_{1}}\right|=\left|\frac{Z_{\mathrm{m}}}{Z_{\mathrm{b}}+Z_{\mathrm{m}}}\right|
$$

The transmission loss of recycled viscoelastic material as an important parameter of the reduction of vibro-acoustic energy can be determined directly by calculation from the measured kinematic quantities of vibration (velocity, acceleration), by the relation

$$
D=10 \lg \frac{\ddot{x}_{1}^{2}}{\ddot{x}_{2}^{2}} \mathrm{~dB}
$$

The methodology presented in this paper can also be applied to other sources of low frequency mechanical vibration, such as continuous layer of the resilient material under the mounting base, etc.

\subsection{Dynamic transmission stiffness of vibration isolators}

The dynamic transmission stiffness is the most typical characteristics of the vibro-acoustic transmission properties of vibro-isolators and/or recycled resilient material for many practical applications. The dynamic transmission stiffness is determined by the elastic, inertia and damping properties of the vibro-isolator. The reason for choosing a presentation of test results in terms of a stiffness is the practical consideration that it complies with data of static and/or low-frequency dynamic stiffness which are commonly used. The additional importance of inertial forces (i.e. elastic wave effects in the vibration isolators) makes the dynamic transmission stiffness at high frequencies more complex than at low frequencies. Because at low frequencies only elastic and damping forces are important, the low-frequency dynamic stiffness is only weakly dependent on frequency due to material properties. In principle the dynamic transmission stiffness of vibro-acoustic isolators is strongly dependent on static preload and temperature. The vibro-sound energy from the base of the vibrating mechanical 
system (input side) to its support (output side) transferred through an isolators or vibro-isolating layer, is thus the result of our compliance with the theory described in this article [3, 12].

A typical approach to the analysis of complex vibratory systems is the use of stiffness compliance - or transmission matrix concepts. The matrix elements are basically special forms of frequency-response functions; they describe linear properties of mechanical and acoustical systems. On the basis of the knowledge of the individual subsystem properties, corresponding properties of assemblies of subsystems can be calculated [15, 17]. The general conceptual framework for the proposed isolator characterization and corresponding real test equipment is shown in Fig. 2 .The system consists of three blocks, which represent the vibration source (mechanical system as a source of vibration), isolator of vibration and the receiving structure respectively.

A fixed contact is assumed at each connection between the source and the isolator and between the isolator and the receiver. To each connection point a force vector $\boldsymbol{F}$ containing three components $F_{x}, F_{y}, F_{z}$ and three moment components $M_{x}, M_{y}, M_{z}$ and a displacement $\Delta \boldsymbol{r}$ containing three orthogonal translational and three orthogonal rotational components are assigned. In Fig. 2 only one component of each of the vectors $F_{1}, x_{1}, F_{2}$ and $x_{2}$ is shown.

The blocked transfer stiffness is suitable for vibro-isolator characterization in many practical cases, the discussion will proceed from the simplest case of unidirectional vibration to the multidirectional case for a single isolator. In the case presented, the damping force is not necessary. For vibration in one direction of a single vibration isolator, the vibro-isolator equilibrium may be expressed by the following equations

$$
F_{1}=k_{1,1} x_{1}+k_{1,2} x_{2} \text { and } F_{2}=k_{2,1} x_{1}+k_{2,2} x_{2}
$$

where stiffness $k_{1,1}$ and $k_{2,2}$ are driving point stiffnesses when the vibration isolator is blocked at the opposite side (i.e. $x_{2}=0, x_{1}=0$, respectively) and $k_{1,2}$ and $k_{2,1}$ are blocked transfer stiffnesses, i.e. they denote the ratio between the force on the blocked side and the displacement on the driven side. For passive isolators $k_{1,2}=k_{2,1}$, because passive linear vibration isolators are reciprocal. Due to increasing inertial forces, $k_{1,1}$ and $k_{2,2}$ become different at higher frequencies. At low frequencies only elastic and damping forces play a role, making all $k_{i, j}$ equal.

The matrix form of equations (6) is

$$
\boldsymbol{F}=[k] \boldsymbol{x}
$$

with the dynamic stiffness matrices

$$
[k]=\left[\begin{array}{l}
k_{1,1} k_{1,2} \\
k_{2,1} k_{2,2}
\end{array}\right]
$$

For excitation of the receiving structure via vibro-isolator

$$
k_{\mathrm{r}}=\frac{F_{2}}{x_{2}}
$$

where $k_{\mathrm{r}}$ denotes the dynamic driving point stiffness of the receiver. From Eq. (6) and Eq. (9) it follows that 


$$
F_{2}=\frac{k_{2,1}}{1+\frac{k_{2,2}}{k_{\mathrm{r}}}} x_{1}
$$

Therefore, for a given source displacement $x_{1}$ the force $F_{2}$ depends both on the isolator driving point dynamic stiffness and on the receiver driving point dynamic stiffness.

However, if $\left|k_{2,2}\right| \leq 0.1\left|k_{\mathrm{r}}\right|$, then $F_{2}$ approximates the so-called blocking force to within $10 \%$, i.e.

$$
F_{2} \approx F_{2, \text { blocking }}=k_{2,1} x_{1}
$$

Because vibration isolators are only effective between structures of relatively large dynamic stiffness on both sides of the isolator of vibration and/or resilient material, Eq. (11) represents the intended situation at the receiving end, therefore these conditions have to be respected when setting up the vibration isolator.

As the block diagram of the source/isolator/receiver system in Fig. 2 shows, the vibroacoustic transmission through isolators depends on the source vibration, the isolator transfer stiffnesses and the receiver driving point stiffnesses. Usually vibrational sources do not vibrate unidirectionally. Therefore, the measurement of isolator stiffnesses for orthogonal directions is of practical interest.

\subsection{Theoretical analysis of the absorption of recycled porous and fibrous materials}

Sound-absorbing materials are widely used in mechanical engineering and even more widely in building and room acoustics. The basic characteristics of these materials is the dependence of the absorption factor on the frequency of propagating acoustic waves. The principle of conversion of sound energy to another type of energy is friction in the structure of the absorbing material, periodic change of acoustic pressure and inelastic deformations (hysteresis) of the material. Upon impact of an acoustic wave on absorbent materials, air molecules oscillate in the pores of this material, reducing their kinetic energy due to friction against the capillary wall and/or fiber (Fig. 3) [13].

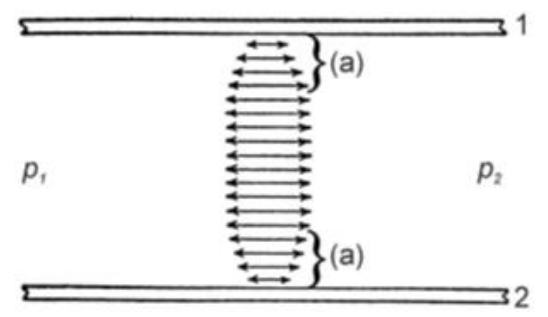

Fig. 3 The behavior of the amplitudes of the velocities of air particles in a sound wave near the surface or fiber

The increase in gas pressure caused by the sound wave is

$$
\Delta p=-\kappa C \Delta V
$$

where $\kappa$ is the adiabatic constant - for air is $\kappa=1.4$;

$C$ - dimensional constant $(\mathrm{N} / \mathrm{m})$. A negative sign indicates that an increase in pressure is accompanied by a decrease in volume $V\left(\mathrm{~m}^{3}\right)$. 
One of the most important quantities needed to determine the absorption properties of porous materials is the flow resistivity $r\left(\mathrm{~N} \cdot \mathrm{s} / \mathrm{m}^{4}\right)$, i.e. the resistance to the flow of gas passing through the structure of the porous material and is defined by

$$
r=-\frac{\Delta p}{d v}=-\frac{A t}{V} \frac{\Delta p}{d}
$$

where $\Delta p$ is the static pressure difference across the material layer of thickness $(\mathrm{Pa})$;

$v$ - particle velocity inside the material sample $(\mathrm{m} / \mathrm{s})$;

$d$ - material thickness (m);

$V$ - volume of gas flowing through the tested sample of material at time $t\left(\mathrm{~m}^{3}\right)$;

$A$ - sample area of one side $\left(\mathrm{m}^{2}\right)$.

The flow resistivity is related to the fiber diameter and the bulk density of the recycled material and can therefore also be calculated according to the equation

$$
r \approx \frac{\eta}{a^{2}}\left(\frac{\rho_{\mathrm{c}}}{\rho_{\mathrm{u}}}\right)^{3 / 2}
$$

where $\rho_{\mathrm{c}}$ is the density of the compressed absorbent material $\left(\mathrm{kg} / \mathrm{m}^{3}\right)$;

$\rho_{\mathrm{u}}-$ density of uncompressed absorbent material $\left(\mathrm{kg} / \mathrm{m}^{3}\right)$;

$\eta$-gas viscosity $\left(\mathrm{N} \cdot \mathrm{s} / \mathrm{m}^{2}\right)$;

$a-$ mean fiber diameter $(\mathrm{m})$.

The specific flow resistance $R_{\mathrm{S}}\left(\mathrm{N} \cdot \mathrm{s} / \mathrm{m}^{3}\right)$ is equal to

$$
R_{\mathrm{S}}=-\frac{A t}{V} \Delta p
$$

Porosity is defined as the ratio of the volume of the pores (cavities) $V_{\mathrm{p}}$ to the total volume of the porous material $V_{\mathrm{u}}$ and, assuming rigid and solid fibers without a binding material, it can be calculated from

$$
\varepsilon_{\mathrm{p}}=\frac{V_{\mathrm{p}}}{V_{\mathrm{u}}}=1-\frac{\rho_{\mathrm{u}}}{\rho_{\mathrm{c}}}
$$

where $\rho_{\mathrm{u}}$ is the density of the (uncompressed) absorbent porous material $\left(\mathrm{kg} / \mathrm{m}^{3}\right)$;

$\rho_{\mathrm{c}}$ - density of the material from which the absorbent porous material is made $\left(\mathrm{kg} / \mathrm{m}^{3}\right)$;

The porosity of absorbent materials is usually in the range of 0.60 to 0.97 . If the material is to absorb sound energy well, the pores must be connected to each other, so that the sound can propagate further through them.

\section{Measurement and analysis of transmission loss of recycled materials}

The measurement of the transmission loss (attenuation) of the samples of resilient (viscoelastic) materials was carried out in accordance with the methodology given in subchapter 2.2 of this article. The signal generator continuously changed the excitation frequency for the selected frequency range from 0 to $400 \mathrm{~Hz}$ sinusoidal signal. The time display of the dynamic load of the test sample with the varying excitation frequency of 
the vibration generated by the exciter is shown in Fig. 4. Observing the course of the increase in the amplitude of the vibration acceleration, smaller outputs can be seen on a relatively smooth time-frequency-amplitude diagram, which characterize the transition through the resonance excited by some components of the test equipment. A more pronounced columned display from the background characterizes the response of the surrounding building structures and the dynamic load of the test equipment from the fancooled signal generator. A comparison of the input and output diagrams shows, in addition to a 10-fold reduction in the amplitude of the vibration acceleration, a reduction in the ambient vibration. The magnitude of the difference in the amplitude of the vibration acceleration between the input and the output characterizes the magnitude of the transmission attenuation of the viscoelastic material. This difference in acceleration amplitudes corresponds to a transmission loss of $20 \mathrm{~dB}$, which is common and sufficient for such types of resilient materials.

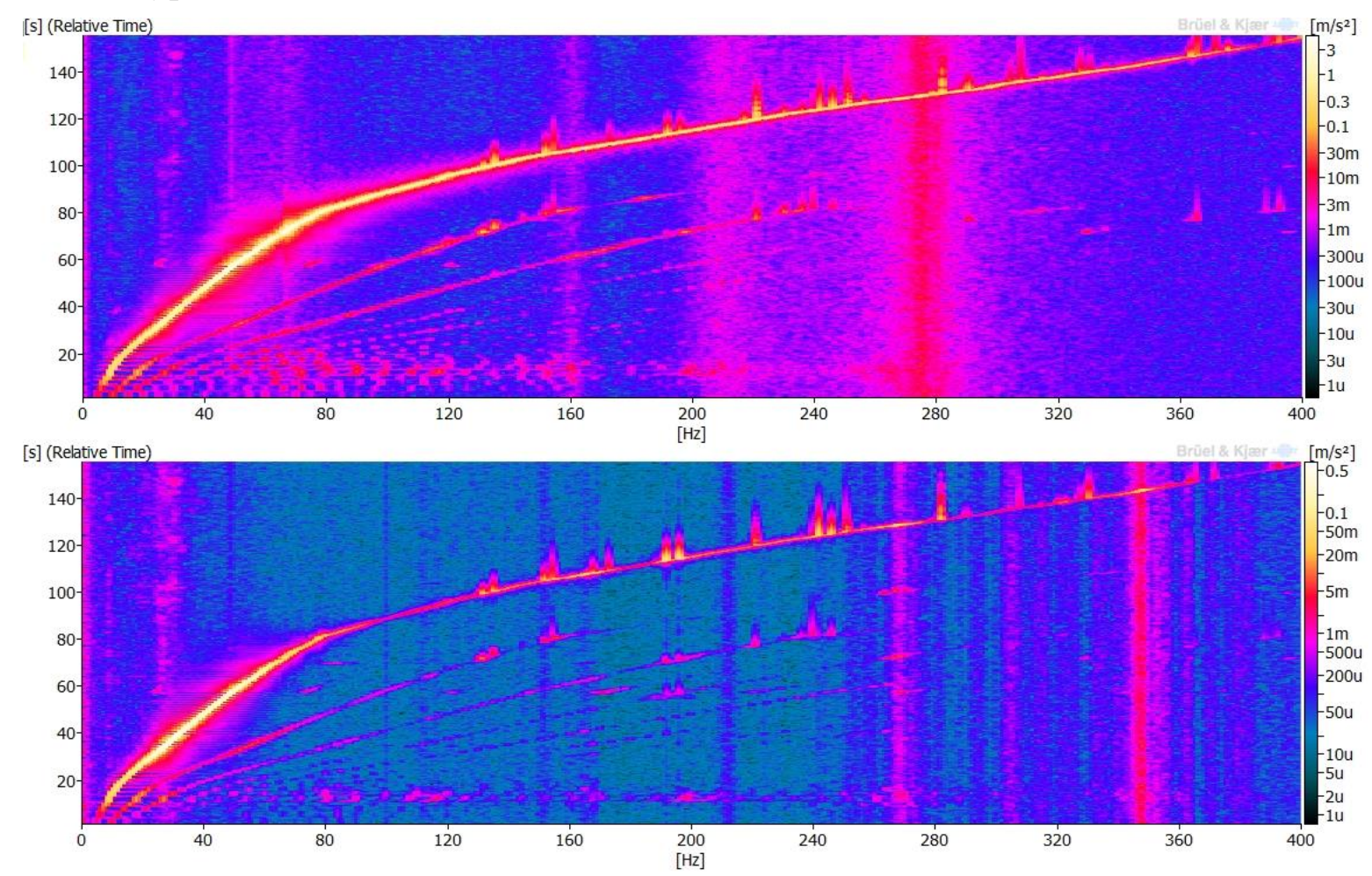

Fig. 4 Time-frequency-amplitude diagram at the input (up) and output (down) of the tested sample of recycled material when measuring the transmission attenuation

The frequency spectrum of the transmission loss for a given resilient material and the excitation frequency at the seismic evaluation limit, which is $33 \mathrm{~Hz}$, is shown in Fig. 5. As it is clear from the spectrum, the application of recycled viscoelastic materials proves (see Chapter 5) that the attenuation at frequencies up to the upper assessment limit of seismic waves is significantly lower than at frequencies above this limit. The value of the transmission loss decreases as the frequency decreases. The use of these materials as vibro-isolators in the field of seismic waves (very low frequencies) is not effective. This fact is also confirmed by the measurements made so far $[15,16,17]$. It is at very low frequencies that the combination of springs and viscoelastic materials is effective. 


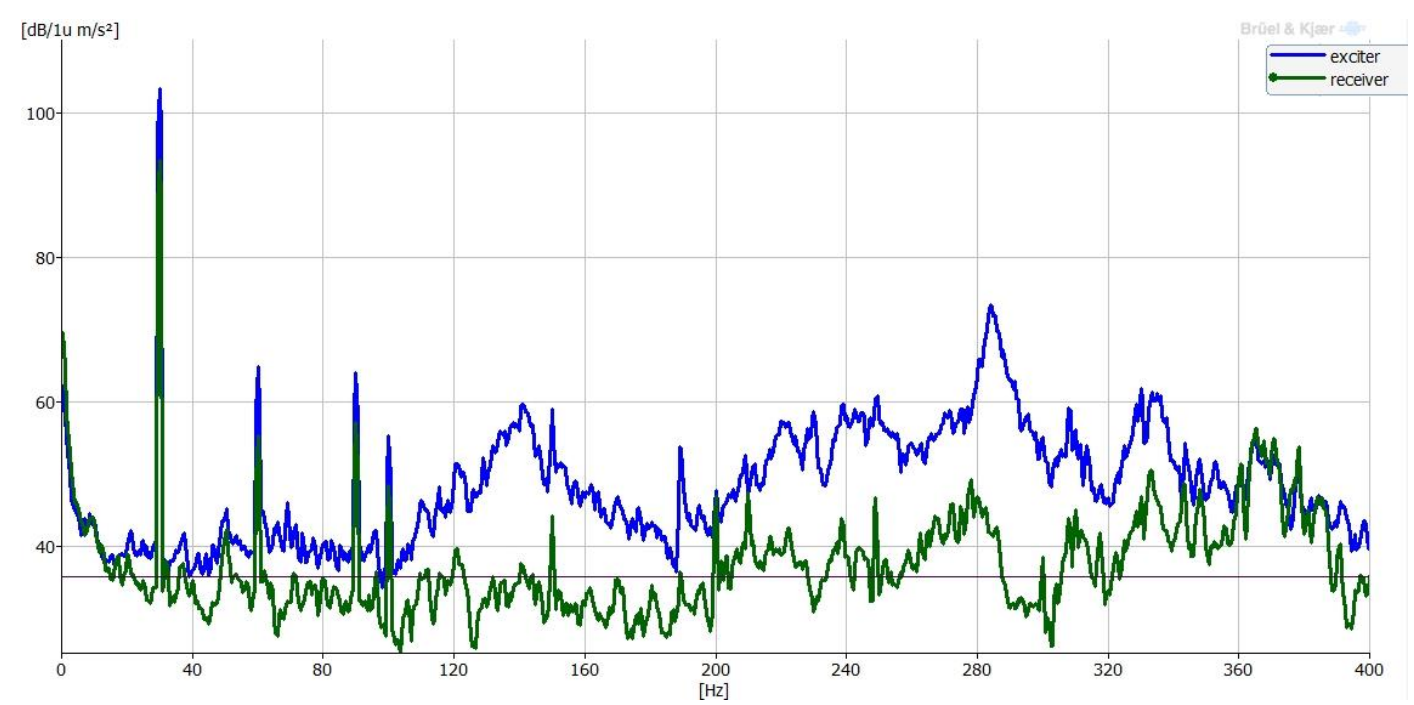

Fig. 5 Frequency analysis of an experimental sample of recycled material at an excitation frequency up to $30 \mathrm{~Hz}$ to measure transmission loss; up exciter and down receiver

The transmission loss (attenuation) for a given viscoelastic material is frequency dependent. This is also confirmed by the experimentally obtained curves in Fig. 6. The transmission loss of recycled viscoelastic materials was obtained from three producers under the trade names STERED, CONIRAP and SYLOMER. It can be seen from the frequency dependence of the transmission attenuation that its value is approximately the same in the monitored frequency band. The transmission loss of viscoelastic materials depends on the geometrical and mass parameters and on their load (see subchapters 3.1 and 3.2). Metrological conditions also have an effect on transmission loss. The best transmission loss results at a defined load were obtained with the combination of viscoelastic materials CONIRAP-STERED (Fig. 6). Based on the theory of wave propagation in a rigid elastic environment, the transmission loss above the observed frequency band is greater $[15,16,17]$. It should be noted that as the excitation frequency increases, the transmission attenuation also increases.

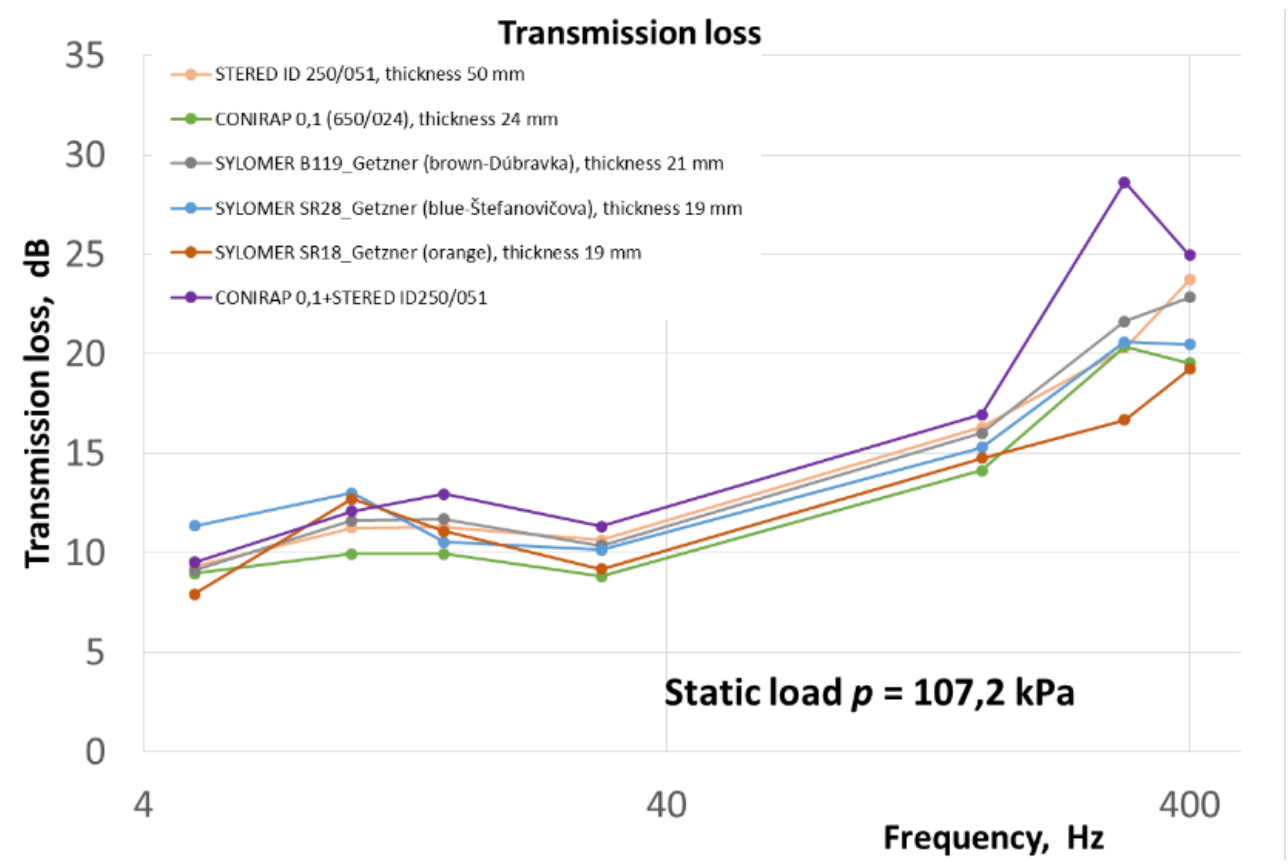

Fig. 6 Transmission loss of various recycled materials depending on the frequency 


\section{Application of recycled resilient materials in practice}

As already mentioned in the introduction, recycled viscoelastic materials are widely used in practice in the field of vibration isolation of machines, technological and building structures and railways. In line with the theory given in subchapter 3.3, porous and fibrous viscoelastic materials also have very good sound-absorbing properties. The use of viscoelastic materials is effective not only in the construction of noise barriers, but also in reducing noise in the indoor environment. When applying viscoelastic materials, vibro-acoustic bridges which significantly reduce transmission loss, must be avoided. This is confirmed by the following two examples. Even if very low frequencies are generated, a combination of springs and viscoelastic materials is desirable.

\subsection{The mounting the 3D seismic exciter [16]}

The effectiveness of the vibration isolation of the seismic exciters base was verified by measuring the transmission of the vibro-sound energy through the isolation layer and into the workplace of the test-room, through the isolated mounting base of a neighboring uniaxial horizontal exciters (Fig. 7) and finally through the building structure. From the frequency analysis in Fig. 7, it is obvious that the low-frequency attenuation is noticeably lower than the attenuation at mid and high frequencies. It should be noted that the attenuation of vibro-sound energy at low frequencies (below $30 \mathrm{~Hz}$ ) is inefficient with the use of resilient materials (recycled rubber and/or textile fabric). Within this frequency range, depending on the static and dynamic load, the natural frequency of the elastic layer of the resilient material used has a natural frequency less than $15 \mathrm{~Hz}$ and therefore, this material is not suitable for attenuation of low frequency vibration. For attenuation of low-frequency vibration (below $15 \mathrm{~Hz}$ ), it is more effective to incorporate, e.g. springs [13]. Relatively small attenuation occurs at $8 \mathrm{~Hz}, 14 \mathrm{~Hz}$ and at the resonance frequency of $24 \mathrm{~Hz}$ of the exciter. These low-frequencies were also recorded by the subjective perception of the operators present in the test-room. The numerical attenuation of low-frequency wave vibration of the vibration isolation for frequencies of $8 \mathrm{~Hz}$, $14 \mathrm{~Hz}$ and $24 \mathrm{~Hz}$ is evident from Fig. 7.

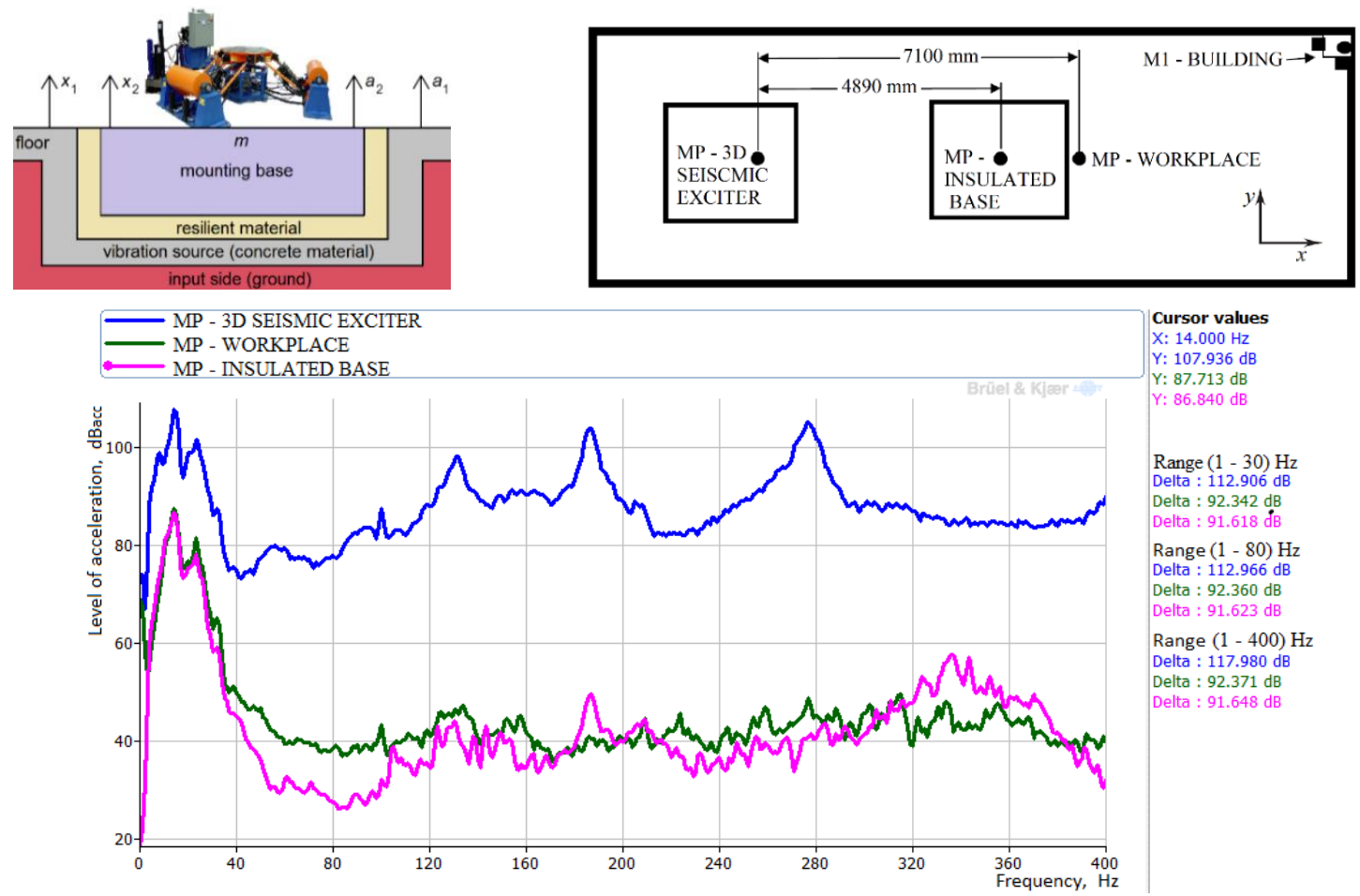

Fig. 7 The distribution of the measurement points (MP) in the test-room with respect to seismic exciter and the frequency spectra in these points [16] 


\subsection{The mounting of the industrial machine [15]}

The machine mounted shown in Fig. 7 and the applicability of the equations given in Chapter 3 is correct provided that the viscoelastic material forms a single transmission path between the vibration source and the receiving structure, which may be the machine itself or the machine environment. In real conditions, there may be mechanical or acoustic parallel transmission paths that cause flanking transmission. For each method of measuring the properties of the isolator, the possible interference of such flanking with the correct measurements must be minimized.

The results of frequency analysis on the mounting base showed that the transmission attenuation of vibration isolation material did not reach the calculated value. The measurement results indicated the formation of flanking transmission that was progressively acting on the fine-grained concrete or cement and caused its flowing back into the gaps between the mounting base and the surrounding environment (floor, ground). To confirm this fact, the experimental sample was created using the same isolation material and the same conditions of excitation. It is clear that there is no flanking transmission and the contact of vibration isolation material is only with the floor (excitation) on the input side and with the concrete block on the output side (receiver). The results are confirmed by the frequency spectra in Fig. 8, where transmission loss at the frequency of $63 \mathrm{~Hz}$ reaches the value of $24.5 \mathrm{~dB}$ for experimental sample (Fig. 8b) and the transmission loss between the measuring input point on the vibration source and output point situated on the mounting base (see Fig. 7) is only approximately half, i.e. $12.7 \mathrm{~dB}$ (Fig. 8a) [15].

a
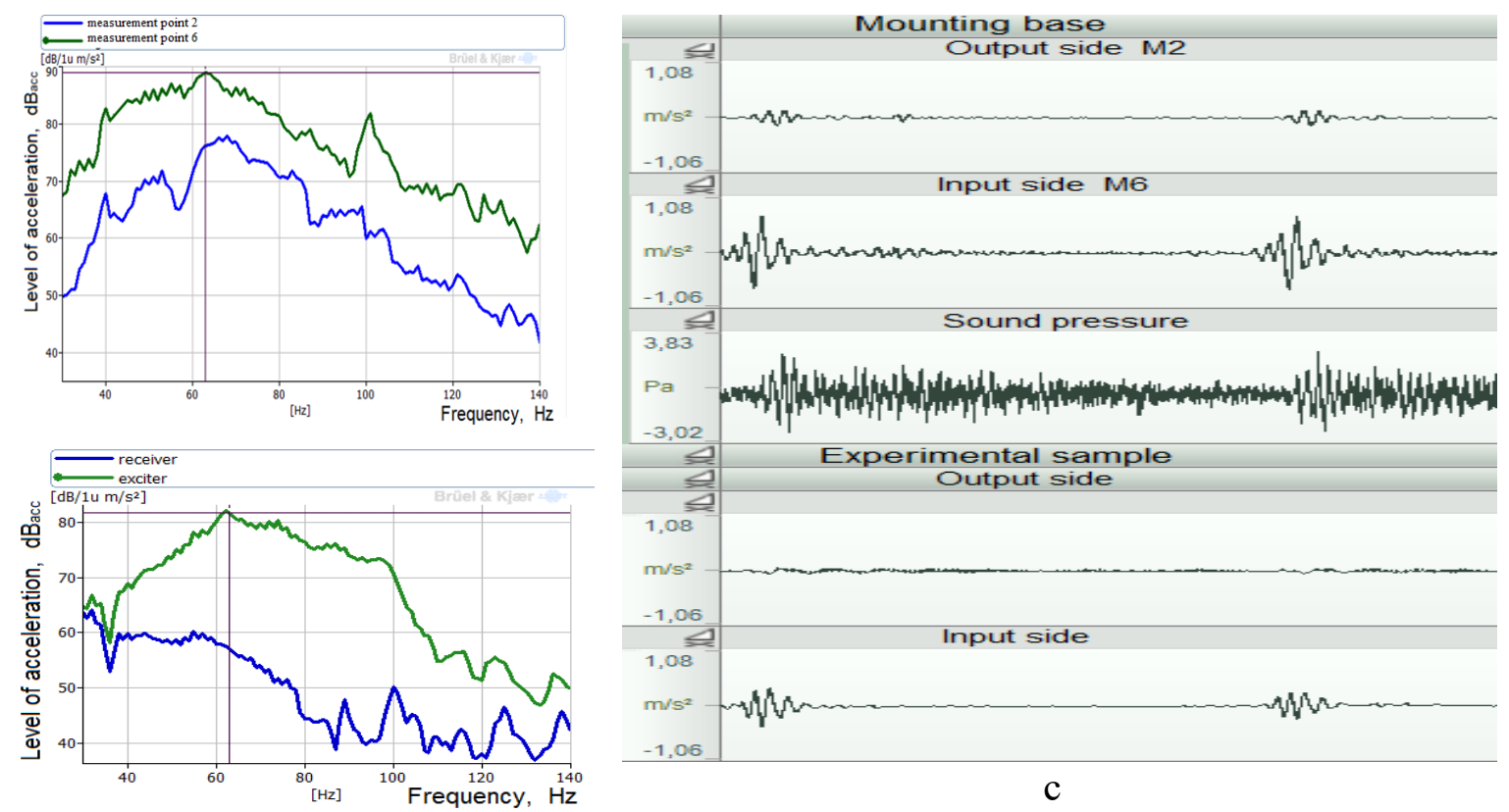

b)

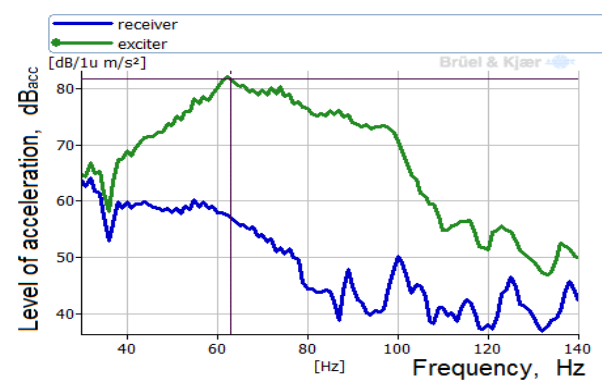

Fig. 8 The autospecta representing the transmission loss excitation input side and mounting base output side (a) and on the experimental sample (b), and time record representing the transmission loss in the mounting base and in the experimental sample (c) [15]

In Fig. 8 it is shown that the value of the maximum acceleration vibration measured on the experimental sample near the mounting base on the concrete block representing the mounting base, is several times lower than that measured on the actual mounting base at the same excitation. In this case, the transmission attenuation value between input and output is more than 10-fold, unlike the 3 -fold transmission attenuation value of the input and output measuring points on the mounting base. The values of maximum acceleration and attenuation on the transmission path for both, the mounting base and the experimental 
sample, under approximately the same dynamic test conditions, confirm the presence of flanking transmission between the mounting plate and the surrounding vibrating environment.

\section{CONCLUSION}

The goal of the paper was to carry out the frequency analysis of the transmission of low and middle frequency vibration through different vibro-isolation elements under varying conditions, and compare the theory of calculating the transmission attenuation as well as the theory of the blocking force which are both necessary when implementing the vibro-isolation elements. The aim of this study was accomplished in this article.

It should be emphasized that vibration and damping in the structure are the two most common means of controlling vibration and sound generated in the structure, especially in the audio frequency range environment in comparison to protect the machines, building and technological structures from ambient vibrations. To achieve the desired effective vibration isolation, some necessary parameters must be met and specific conditions must be created [12, 13]. Before implementing vibration isolation, it is very important to obtain the frequency spectrum of the vibration source. Using the above specified theory, it is possible to calculate a material transmission loss which is required for isolation.

The theory and given methods can be used for the calculation of vibration transmissibility of a recycled resilient material used for vibro-isolation, which has a wide application in the field of mechanical and civil engineering. The theory and method discussed in this paper are applicable to all materials that behave approximately linearly. The method can be used for two or more layers forming a plate-like shape. The accuracy and reproducibility of the measured transmissibility is expected to be around $10 \%$. Reproducibility will depend on the linearity of the flexible material, the accuracy of the mechanical impedance value $Z_{\mathrm{m}}$ or other part of the body and other measurement parameters such as test conditions (e.g. sample shape, temperature, humidity) and the properties of the test material (e.g. non-linearity, aging).

The results of this article also confirm the adverse effects of low-frequency waves. The low-frequency noise and vibrations generated mainly by machine systems have a negative impact both, on the mechanical system itself and also on human well-being. The problem of low-frequency sources of vibration, their transmission and impact on machines, structures and the human has recently become the subject of a lot of research on a global scale since the long-term exposure may result in damage to physical and mental health [1, 2]. Reducing the intensity of structural-borne noise by effective vibration isolation will thus result in reduction of noise levels in the workplace and in the natural environment [5].

\section{ACKNOWLEDGEMENT}

The research presented in this paper is an outcome of the project No. APVV-19-0538 "Progressive hybrid high-speed spinning actuator" funded by the Slovak Research and Development Agency and

\begin{tabular}{|c|c|c|}
\hline$\frac{{ }^{\star}}{{ }^{*} \star \star^{*}}$ & $\begin{array}{l}\text { OPERAČNÝ PROGRAM } \\
\text { VÝSKUMA INOVÁCIE }\end{array}$ & $\begin{array}{l}\text { This contribution was elaborated within execution of the project "New generation } \\
\text { of freight railway wagons" (Project code in ITMS2014+:313010P922), on the basis } \\
\text { of support of the operational program Research and innovation financed from the } \\
\text { European Regional Development Fund. }\end{array}$ \\
\hline
\end{tabular}

\section{REFERENCES}

[1] Argalasova L., Lekaviciute J., Jeram S., Sevcikova L., Jurkovicova J. "Environmental Noise and Cardiovascular Disease in Adults", Noise Health 62, pp. 22 - 31, 2013. 
[2] Balazikova, M., Sinay, J. "Implementation of Auditory and Non-auditory Effects of Noise in the Risk Assessment Process in Mechanical Engineering", Procedia Engineering 48, pp. $621-628,2012$.

[3] Čulík, M., Jochim, S., Ondrejka, V. "Sound insulation of partition wall and ceiling in panel timber frame structure". Akustika 31, pp. 145 - 152, 2019. ISSN 1801-9064

[4] Darula, R., Ziaran, S. "An experimental study of optimal measurement point location for gear wheel state-of-wear measurements by means of vibro-acoustic diagnostics", Strojnícky časopis Journal of Mechanical engineering 62 (2), pp. 61 - 80, 2011.

[5] Flimel, M. "Possibilities of active reduction of noise in the workplace", Akustika 28, pp. $27-31,2017$.

[6] Izrael, G., Bukoveczky, J., Gulan, L. "Influence of nonstandard loads onto life of chosen modules of mobile working machines”, Machine Design 3 (1), pp. 13 - 16, 2011.

[7] Randall, R. B. "Vibration-based Condition Monitoring", John Wiley and Sons, 309 p. 2011. ISBN 978-0-470-97765-1

[8] Segla, S. "Modelling and Optimization of Passive and Semi-active Suspension of a 3 DOF Seat Platform", The 15th IFToMM World Congress, Krakow, Poland, Springer Nature Switzerland AG 2019, pp. 4075 - 4084, 2019. ISSN: 22110984

[9] Šooš, L., Kováč, P., Križan, P., Beniak, J., Matúš, M. "New Design of Compacting Machines and Biofuel Shapes". American Advanced Materials Congress, Miami/USA, 2016.

[10] Žiaran, S. "Technical diagnostics", Scientific monograph. Issued by STU Bratislava, pp. 332, 2013. ISBN 978-80-227-4051-7 (in Slovak).

[11] Ziaran, S., Musil, M., Cekan, M., Chlebo, O. "Analysis of Seismic Waves Generated by Blasting Operations and their Response on Buildings", International Journal of Environmental, Earth Science and Engineering 7 (11), 2013.

[12] Žiaran, S. "Low-frequency noise and vibration”, Scientific monograph. Issued by STU Bratislava 2016, pp. 316, 2016. ISBN 978-80-227-4536-9 (in Slovak).

[13] Ziaran, S. "Vibration and acoustics. Vibration and noise control in industry", Monograph, Issued by Slovak University of Technology in Bratislava, pp. 330, 2006. (in Slovak).

[14] Ziaran, S., Chlebo, O. "Noise Control Transmission Methods of the Combustion Engine by Means of Reduction of the Vibration", Archives of Acoustics 41 (2), pp. 277 - 284, 2016.

[15] Žiaran, S., Chlebo, O. "The Transmission of Vibro-acoustic Energy from the Industrial Machines through the Building Structure to the Mounting Base”, ICSV24, London, 23 27 July, 2017.

[16] Ziaran, S., Chlebo, O., Cekan, M. "Effects of the mounting of the 3D seismic exciter on the working environment and surrounding structures", 25th International Congress on Sound and Vibration 2018: Hiroshima Calling 4, pp. 2490 - 2497, 2018. ISBN: 978$151086845-8$

[17] Ziaran, S., Chlebo, O., Musil, M. "Analysis of the impact of different types of vibration isolation on the dynamic loading of machines and the surrounding environment". Proceedings of Internoise/ASME NCAD Noise control and acoustics division conference, 2018, Article number: IN2018-6135, 2018. 
[18] Ziaran, S., Hucko, B., Chlebo, O., "Impact of vibro-isolation of technical equipment on structure-borne noise in living areas". Proceedings of the 26th International Congress on Sound and Vibration 2019, Montreal Canada, 2019. ISBN: 978-199918100-0

[19] Ziaran, S., Chlebo, O., Cekan, M., Tuma, J. "Transmission of Vibrations through Vibration Isolators, Theory and Application". The 15th IFToMM World Congress, Krakow, Poland, Springer Nature Switzerland AG 2019, pp. 3995 - 4004, 2019.

[20] ISO 5348, Mechanical vibration and shocks. Mechanical mounting of accelerometers. 